\title{
MANAJEMEN DESAIN LINGKUNGAN PENDIDIKAN ANAK USIA DINI DI PUSAT TUMBUH KEMBANG ANAK PENDIDIKAN ISLAM ANAK USIA DINI ALAUDDIN MAKASSAR
}

\author{
Sitti Mania \\ Jurusan Pendidikan Matematika \\ Fakultas Tarbiyah dan Keguruan, UIN Alauddin Makassar \\ E-mail: sitti.mania@uin-alauddin.ac.id \\ Nurhasanah \\ Jurusan Pendidikan Islam Anak Usia Dini \\ Fakultas Tarbiyah dan Keguruan, UIN Alauddin Makassar \\ E-mail: nurhasanahsultan077@gmail.com \\ Nurbaeti Syam \\ Jurusan Pendidikan Islam Anak Usia Dini \\ Fakultas Tarbiyah dan Keguruan, UIN Alauddin Makassar \\ E-mail: nurbaetisyam4798@gmail.com

\section{Shermila} \\ Jurusan Pendidikan Islam Anak Usia Dini \\ Fakultas Tarbiyah dan Keguruan, UIN Alauddin Makassar \\ E-mail: shermilamila883@gmail.com \\ Fitriani K. \\ Jurusan Pendidikan Islam Anak Usia Dini \\ Fakultas Tarbiyah dan Keguruan, UIN Alauddin Makassar \\ E-mail: fitri170597@gmail.com
}

\begin{abstract}
Abstrak
Penelitian ini bertujuan untuk mengetahui gambaran penataan atau pengelolaan desain lingkungan Pendidikan Anak Usia Dini (PAUD) baik lingkungan psikis maupun fisik (indoor dan outdoor) di Pusat Tumbuh Kembang Anak (PTKA) Pendidikan Islam Anak Usia Dini (PIAUD) Alauddin Kabupaten Gowa. Jenis penelitian ini merupakan penelitian kualitatif dengan satu subjek yakni guru PTKA PIAUD Alauddin. Kabupaten Gowa. Data dikumpulkan menggunakan tehnik wawancara terstruktur yang hasilnya menggunakan deskriptif. Hasil penelitian menunjukkan bahwa PTKA PIAUD Alauddin berusaha menciptakan lingkungan psikis melalui pendekatan guru terhadap peserta didik agar anak merasa nyaman ketika berada di sekolah. Sedangkan untuk desain lingkungan fisik (indoor dan outdoor) guru selalu mengedepankan prinsip pengelolaan Lingkungan PAUD yakni: keserasian, keseimbangan, keamanan, dan kesatupaduan. Lingkungan outdoor cukup luas untuk anak bereksplorasi, terdapat beberapa alat permainan edukatif yang dapat mengembangkan berbagai aspek perkembangan anak seperti perosotan, tempat climbing, rumah-rumahan serta terowongan. Lingkungan indoor terdiri dari beberapa ruangan yaitu ruangan belajar, ruangan tidur dan toilet.
\end{abstract}


Kata Kunci: Desain Lingkungan, Manajemen, Pendidikan Anak Usia Dini

\begin{abstract}
This study aims to study the description of the design or managementof the design of Early Childhood Education (PAUD) in both the physical and indoor environments at the Alauddin Early Childhood Education Center (PIAUD) Islamic Education Center in Gowa Regency. This type of research is qualitative research with one subject, namely PTKA PIAUD Alauddin teacher. Gowa Regency. Data collected using structured interview techniques obtained using descriptive. The results showed that PTKA PIAUD Alauddin tried to create a psychological environment through asking teachers to learners so that children would be comfortable compiling at school. While for the design of Physical Environment (indoor and outdoor) teachers always prioritize the principles of PAUD Environmental Management, namely: harmony, balance, security, and harmony. The external environment is wide enough for children to explore, there are several educational games that can develop various kinds of children's development such us slides, climbing places, houses and navigation. The indoor environment consists of several rooms, namely the study room, bedroom and toilet.
\end{abstract}

Keywords: Environmental Design, Management, Early Childhood Education

\title{
PENDAHULUAN
}

Pendidikan Anak Usia Dini (PAUD) menurut Mulyasa (2012) merupakan peletak dasar pertama dan utama dalam pengembangan pribadi anak; baik berkaitan dengan karakter, kemampuan fisik, kognitif, bahasa, seni, sosial emosional, spiritual, disiplin diri, konsep diri, maupun kemandirian. Mariyana, dkk (2010) menjelaskan management berasal dari kata "to manage" yang berarti mengatur, melaksanakan, mengelola, mengendalikan, dan memperlakukan. Namun kata management sendiri sudah diserap ke dalam bahasa Indonesia menjadi kata manajemen yang berarti sama dengan istilah "pengelolaan", yakni sebagai suatu proses mengoordinasi dan mengintegrasikan kegiatan-kegiatan kerja agar dapat diselesaikan secara efisien dan efektif

Lingkungan secara harfiah menurut kamus besar Bahasa Indonesia, lingkungan diartikan sebagai suatu tempat yang mempengaruhi pertumbuhan manusia, sedangkan menurut kamus Bahasa Inggris emvironment diartikan sebagai sesuatu yang berhubungan dengan lingkungan atau suasana. Jika dikombinasikan pengertian istilah lingkungan kedua dari kedua bahasa tersebut, maka lingkungan dapat diartikan sebagai tempat atau suasana (keadaan) yang dapat mempengaruhi pertumbuhan dan perkembangan seseorang (Mariyana, dkk., 2010).

Manajemen desain lingkungan PAUD menurut Suyadi (2011) adalah penataan tepatnya set plan tampilan indoor maupun outdoor PAUD. Walaupun kegiatan mendesain penampilan indoor maupun outdoor PAUD bukan keahlian guru, tetapi setidaknya guru PAUD dapat mengenali karakter desain PAUD yang sesuai dengan dunia fantasi anak. Sebab, dunia fantasi anak berpengaruh besar terhadap 
perkembangan kognitif, sosial, emosi, bahasa, seni, dan lain sebagainya.

Menurut Mariyana, dkk (2010) menjelaskan bahwa periode usia TK atau prasekolah adalah masa peka. Anak sensitif untuk menerima segala rangsangan, yaitu pada masa fungsi-fungsi fisik dan psikis telah siap merespons segala rangsangan (stimulus) yang diberikan oleh lingkungan. Dengan demikian, lingkungan sebagai unsur yang mensuplai atau menyediakan sejumlah rangsangan perlu mendapatkan perhatian sungguh-sungguh. Diperlukan perencanaan dan seleksi khusus agar agar dapat menyediakan lingkungan yang cocok dan diperlukan oleh anak. Ketepatan lingkungan yang disediakan akan memberi pengaruh pada proses dan hasil perilaku anak, baik secara langsung maupun tidak langsung.

Montessori, sama halnya dengan Piaget, menganggap lingkungan sebagai kunci utama pembelajaran spontan anak. Lingkungan di sini hendaknya yang menyenangkan bagi anak dan juga memberi kesempatan bagi perkembangan potensi masing-masing individu. Menurut Montessori, anak adalah an active agent (agen aktif) dalam lingkungannya, sementara guru merupakan fasilitator yang membantu pembelajaran dan perkembangan anak (Hidayatulloh, 2014).

Suyadi (2011) menjelaskan bahwa menata atau mengelola penampilan indoor maupun outdoor PAUD tidak bisa dilakukan sembarang orang. Orang yang mampu mengerjakan hal ini adalah mereka yang berasal dari pendidikan seni atau pendidikan desain. Merekalah yang mampu memilih komposisi warna dan guratgurat corak serta khas lukisan yang dapat melejitkan dunia fantasi anak. Inilah sebabnya, mengapa guru PAUD sekalipun tidak berkompetensi di bidang ini. Sebab, proses pembuatan desain PAUD hampir melibatkan seluruh unsure seni artistik yang ada. Lebih dari itu, seni artistik yang dimaksud harus disesuaikan dengan dunia fantasi anak, sehingga setting indoor maupun outdoor pembelajaran dapat menambah suasana ceria anak.

Jika lingkungan PAUD didesain berdasarkan pemahaman terhadap semua unsur ke-PAUD-an (kurikulum, proses pembelajaran, tumbuh kembang anak, dan lain sebagainya) maka setiap jengkal lingkungan PAUD bisa menjadi cerminan program, tujuan, visi dan misi kelembagaan. Konsep desain lingkungan PAUD dengan landasan filosofis yang kuat sangat dibutuhkan, khususnya dalam penataan ruang, pemetaan fungsi lahan, tata letak bangunan, dan lain sebagainya. Lebih dari itu, hiasan, khususnya lukisan sangat membutuhkan desain yang berdasarkan pemikiran filosofis yang mendalam. Mulai dari pemilihan komposisi warna, corak lukisan yang dipakai, objek yang akan dilukis, dan yang tidak kalah pentingnya adalah makna filosofis di balik lukisan tersebut (Suyadi, 2011: 212).

Lingkungan menyenangkan, menurut perspektif Montessori yang dipaparkan oleh Hidayatulloh (2014) memiliki karakteristik sebagai berikut: (1) accessibility and availability (mudah diakses dan tersedia). Kebanyakan anak menyukai area terbuka yang dapat digunakan untuk berbagai aktivitas individu maupun kelompok. Montessori menganjurkan pula bahwa taman area terbuka hendaknya memiliki area 
tertutup juga, sehingga memungkinkan untuk digunakan anak dalam berbagai cuaca. Organisasi materi atau alat-alat, aktivitas, dan kesibukan lain juga merupakan aspek lingkungan menyenangkan yang menawarkan ketersediaan dan kemudahan akses. Secara umum, tiap-tiap aktivitas memiliki areanya yang mendukung anak untuk bebas memilih; (2) freedom of movement and choice (ada kebebasan bergerak dan memilih). Terkait dengan hal ini, guru hendaknya memiliki rasa percaya dan hormat kepada anak. Anak akan bisa menentukan pilihan yang "tepat" jika ia memiliki kesempatan untuk bergerak ke mana pun yang ia suka, dan menemukan apa yang ia butuhkan untuk memuaskan dirinya; (3) personal responsibility (penuh tanggung jawab personal). Pemberian kebebasan perlu didukung dengan pelatihan sikap bertanggung jawab kepada anak. Sikap ini bisa dibentuk misalnya dengan melatih seorang anak untuk mengembalikan mainan atau sarana belajar ke tempatnya semula; (4) reality and nature (nyata dan alami). Model nyata seperti benda 3D (tiga dimensi) dianggap lebih representative daripada 2D (dua dimensi). Misalnya, penggunaan kerangka tubuh manusia berbentuk 3D akan lebih mudah dicerna oleh anak dibandingkan gambar 2D. Kesan alami akan tampak ketika anak diberikan kesempatan lebih untuk bereksplorasi melalui berkebun, kelas alam, dan segala aktivitas yang bersentuhan lengsung dengan alam. Kelas indoor pun akan terlihat lebih alami ketika dihiasi dengan bunga atau tanaman yang asli, bukan buatan; (5) beauty and harmony (indah dan selaras). Aspek keindahan bisa diperoleh misalnya dari dekorasi ruangan yang sederhana, artinya tidak berlebihan dan tidak mengalihkan perhatian anak. Sedangkan kesan selaras bisa didapat dari ketepatan pengorganisasian ruang belajar. Montessori menyarankan agar ruang kelas tidak terlalu sunyi, tetapi juga tidak ramai atau semrawat. Sebagaimana yang ada di Casa Dei Bambini, ruang kelas bagi anak usia 3-6 tahun di sana dinilai menyenangkan, sehingga anak bisa santai dan merasa seperti di rumah sendiri.

Peneliti menarik melakukan penelitian di PTKA PIAUD Alauddin karena lokasi PTKA berada di sebuah Universitas yang kebetulan juga tempat peneliti menempuh pendidikannya. Selain itu PTKA PIAUD Alauddin memiliki ruangan tidur yang cukup menarik untuk diteliti, terkait dengan desain lingkungannya, seperti letak ruangan, penyediaan kasur tidur serta penataannya, pengantar tidur yakni musik murottal dan lain sebagainya.

Penelitian ini bertujuan untuk mengetahui bagaimana manajemen desain lingkungan PTKA PIAUD Alauddin, meliputi desain lingkungan indoor dan outdoo, serta optimalisasi pemanfaatan lingkungan PTKA.

\section{METODE PENELITIAN}

Jenis penelitian merupakan penelitian kualitatif. Subjek dalam penelitian ini yang menjadi sumber informan utama berjumlah satu orang yaitu guru dari PTKA PIAUD Alauddin yang beralamat di Jalan H.M. Yasin Limpo No. 36, Kelurahan Samata, Kecamatan Somba Opu, Kabupaten Gowa, Sulawesi Selatan. Adapun pemilihan 
subjek berdasarkan kriteria sekolah: (1) Guru bersedia menjadi subjek penelitian; (2) Mudah diakses oleh peneliti; (3) Memiliki lingkungan indoor dan outdoor.

Data dikumpulkan dengan teknik wawancara terstruktur yang disusun sendiri oleh peneliti dengan cara memberi seperangkat instrument penelitian berupa pertanyaan kepada responden untuk dijawab berdasarkan alternative jawaban yang telah tertera dalam pedoman wawancara mengenai manajemen desain lingkungan PAUD. Peneliti melakukan wawancara dengan informan dan peneliti sendiri yang melingkari jawaban yang diberikan oleh responden. Data yang sudah terkumpul dianalisis menggunakan analisis deskriptif.

\section{HASIL DAN PEMBAHASAN}

Obyek yang diteliti adalah tatanan atau pengelolaan tampilan indoor maupun outdoor PTKA PIAUD Alauddin. Data penelitian didapatkan dari hasil wawancara dengan salah satu guru yang ada di PTKA UIN Alauddin Makassar Samata Gowa. Sebagaimana halnya dengan keluarga dan institusi social lainnya, Slameto (dalam Arianto, 2015) mengungkapkan "sekolah merupakan salah satu institusi social yang mempengaruhi proses sosialisasi dan berfungsi mewariskan kebudayaan masyarakat kepada anak, sekolah merupakan suatu sistem sosial yang mempunyai organisasi dan pola relasi sosial diantara para anggota yang unik". Ini kita sebut dengan kebudayaan sekolah.

Terdapat dua lingkungan belajar yang penting untuk mendapat perhatian dari pihak pengelola sekolah yaitu : Pertama, lingkungan psikis. Guru di PTKA PIAUD Alauddin selalu berusaha memberikan perhatian dan pengawasan kepada peserta didik, misalnya ketika ada seorang anak yang menampakkan wajah murung dan kurang semangat guru berusaha mendekati dan mencari tahu penyebabnya, sebagai bentuk perhatian guru terhadap siswanya. guru juga selalu berusaha menghilangkan rasa bosan peserta didik saat belajar.

Pada saat-saat tertentu anak ingin didengarkan, pada saat itu kita perlu menghentikan kegiatan yang tengah dilakukan, berbaliklah kepada anak dan katakana padanya "Apakah kamu ingin bicara dengan bunda sekarang?" jika anak mengatakan iya, maka luangkanlah waktu untuk mendengarkannya terlebih dahulu, Anda bisa mengatakan "Baiklah, bunda akan matikan dulu kompornya, agar bunda bisa mendengarkan ceritamu dengan fokus." Atau jika pekerjaan Anda benar-benar tidak bisa ditinggal, maka Anda dapat berkata "Maaf sayang, bunda ingin sekali mendengarnya sekarang, tetapi tugas bundatidak dapat ditinggalkan. Bagaimana jika kita bercerita setelah makan malam?" Anda wajib untuk mendengarkan ceritanya yang tertunda setelah makan malam usai. Dan, saat anak bercerita maka perhatikanlah (Latif dkk., 2013).

Jadi, guru sebaiknya mendengarkan dengan penuh perhatian agar anak merasa dihargai, sehingga tercipta lingkungan psikis yang baik.

Salah satu cara menciptakan lingkungan psikis yang baik agar anak merasa 
nyaman dan senang belajar yaitu memberikan reward seperti pujian atau hadiah apabila anak melakukan pencapaian baik. Sedangkan cara mendisiplinkan anak yaitu dengan tidak memulai pembelajaran apabila kondisi masih terjadi kegaduhan, serta memberikan punishment seperti peringatan (tetapi dengan kalimat yang baik) kepada anak.

Kedua, lingkungan fisik. Menurut Evertson \& Emmer (2011) menjelaskan bahwa mengatur lingkungan fisik bagi pengajaran merupakan titik mula yang logis untuk pengelolaan ruang kelas karena hal ini merupakan sebuah tugas yang dihadapi semua guru sebelum sekolah mulai. Banyak guru merasa lebih mudah merencanakan aspek pengelolaan ruang kelas lainnya begitu mereka mengetahui bagaimana unsur-unsur fisik dari ruang kelas akan diatur.

Tujuan utama penataan lingkungan fisik kelas menurut Prapsiwi (2012) ialah mengarahkan kegiatan siswa dan mencegah munculnya tingkah laku siswa yang tidak diharapkan melalui penataan tempat duduk, perabot, pajangan, dan barangbarang lainnya di dalam kelas.

PTKA PIAUD Alauddin terletak di lantai dasar salah satu fakultas di UIN Alauddin Makassar, sehingga lingkungan kurang kondusif karena banyak orang yang lalu lalang, meskipun begitu tempatnya tetap bebas dari asap rokok dan pestisida serta bebas dari bahan yang mudah terbakar atau rapuh.

Lingkungan fisik terbagi atas dua yaitu: Pertama, outdoor. Menurut Suyadi (2011) selain sarana prasarana di dalam ruang (indoor) lembaga PAUD juga harus melengkapi sarana prasarana di ruang terbuka (outdoor) atau lapangan. Isinya sama, yakni berbagai fasilitas pembelajaran atau permainan. Hanya saja, bentuk dan jenisnya lebih bervariasi sesuai dengan kondisi luar ruangan yang ada.

Melalui aktivitas fisik di luar ruangan atau outdoor semua bagian perkembangan anak dapat ditingkatkan. hal ini terjadi karena aktivitas outdoor melibatkan multi aspek perkembangan anak. Aktivitas outdoor lebih berperan dalam mengintegrasikan sensoris dan berbagai potensi yang dimiliki anak. Hal ini termasuk perkembangan fisik, keterampilan sosial dan pengetahuan budaya, serta perkembangan emosional dan intelektual (Mariyana \& Setiasih).

Di lingkungan outdoor cukup luas sehingga anak dapat bergerak bebas. Desain ketinggian pagar cukup mencegah anak dapat keluar lembaga, pagar terbuat dari kayu yang mengelilingi lokasi outdoor. Terdapat beberapa permainan seperti perosotan, ada 3 alat permainan perosotan yaitu, 1 perosotan dengan tangga, 1 perosotan yang sepaket dengan jembatan dan tempat climbing berupa tali, terdapat pula rumah-rumahan yang juga sepaket dengan perosotan. Karena lokasi outdoor berada di lantai dasar yang bukan tanah, jadi alas dari tempat outdoor yaitu karpet puzzle agar lingkungan outdoor tetap aman. Mainan outdoor bebas dari bahan berbahaya, seperti perosotan dilapisi dengan steroform, rumah-rumahan terbuat dari plastik dengan alas karpet puzzle juga.

Kedua, indoor. Lingkungan indoor berupa ruangan tempat belajar, ruangan 
tidur, dan toilet. Lantai di setiap ruangan mudah dibersihkan, pegangan pintu setiap ruangan setinggi jangkauan anak, serta stop kontak tidak mudah dijangkau anak.

Lingkungan belajar di dalam ruangan akan digunakan tempat belajar bagi anak-anak untuk mengasah berbagai potensinya. Hal yang menjadi perhatian setidaknya meliputi ukuran ruangan, keadaan lantai, dinding kelas, atap langit-langit dan lain-lain yang diperlukan dalam pengelolaan lingkungan belajar yang nyaman dan menyenangkan (Mariyana, dkk. dalam Mariyana \& Ocih).

Di PTKA PIAUD Alauddin terbagi atas beberapa ruangan yaitu: Pertama, ruangan tempat belajar. Ruangan tempat belajar terdiri dari: (1) ruangan tempat belajar berukuran cukup luas dengan lantai yang dilapisi karpet tebal. kemudian sebagian sisinya di lapisi kembali dengan karpet puzzle yang berwarna-warni dengan beberapa item seperti Alphabet, angka, buah, kendaraan, hewan dan lain-lain; (2) penggunaan cat tembok tidak mudah luntur; (3) perabot menggunakan warna yang menarik perhatian anak, dan sebisa mungkin juga menjadi sumber belajar; (4) buku ditempatkan di tempat yang mudah dijangkau oleh anak; (5) alat permainan indoor disimpan dengan mengelompokkan berdasarkan jenis permainannya dalam box-box, misalnya bola, puzzle, lego, mainan buah dan mainan alat dapur, plastisin, mobilmobilan dan lain-lain; (6) lemari tempat ATK, Bedak, perlengkapan mandi dan lainlain.

Suyadi (2011) menjelaskan bahwa dengan tersedianya ruang sebagai kawasan bebas gerak, orang tua bisa mengalihkan kreativitas anak sehingga berbagai larangan terhindar dari anak. Seandainya orang tua terpaksa "melarang" anaknya supaya tidak mencoret-coret dinding ruang tamu, misalnya, ia bisa mengalihkan agar mencoret-coret dinding aula saja; demikian pula ketika ia ingin memanjat meja makan yang di atasnya terdapat piring dan gelas, ia bisa mengalihkan anak agar memanjat meja yang ada di aula saja; atau ketika anak ingin memegang dan membawa semua benda antik di ruang tamu, misalnya, orang tua dapat mengalihkan kepada benda-benda lain yang memang untuk permainan anak.

Kedua, ruangan tidur. Ruangan tidur terletak di samping ruang belajar, terdapat beberapa fasilitas seperti: (1) loker setiap anak yang berwarna-warni dan mudah dijangkau anak; (2) kasur lengkap dengan sepreinya; (3) speaker dengan musik murottal sebagai pengantar tidur. Menurut Suyadi dalam Suyadi (2011) mengatakan bahwa telah banyak penelitian yang menunjukkan bahwa musik dapat membantu prestasi anak dalam banyak hal. Sekadar Sekolah St. Augustine School of the Arts, Amerika, yang hampir semua peserta didiknya berasal dari keluarga miskin dan terbelakang sangat senang belajar, terlebih lagi ketika belajar musik. Mereka sangat bersemangat belajar musik, sampai-sampai mengambil les di luar sekolahnya untuk bermain musik. Hasilnya? Anak didik di sekolah ini mempunyai prestasi akademik yang termasuk paling tinggi di seluruh Amerika. Lebih dari itu, survei membuktikan bahwa tiga dari 17 negara yang peserta didiknya setingkat SMP, unggul di bidang sains adalah negara yang memasukkan pelajaran musik dengan 
sangat intensif di dalam kurikulum sekolahnya. Ketiga negara tersebut adalah Hongaria, Jepang, dan Belanda (Adi W. Gunawan, 2003). Hal ini diperkuat oleh berbagai penelitian di berbagai disiplin ilmu yang menunjukkan bahwa orang yang mengarang cerita atau menulis dengan diiringi musik jauh lebih kreatif dan imajinatif daripada yang bekerja di tengah keheningan atau suasana sepi dan sunyi. Sebagai contoh, seorang penyiar terkenal dari Amerika Abad ke-20, Hart Crane. la dikenal sebagai pemakai rambu Cuba dengan mengobarkan lagu atau rekaman Bolero dari Ravel sebelum ia mulai. Bahkan, ia tidak akan berhenti menulis kecuali mengganti kaset rekamannya. Konon, ia tidak pernah keluar dari kamar keranjingannya sebelum berhasil menulis puisi terbaiknya; (4) rak tempat alat sholat; (5) tempat sampah. Karena ruangan masih terbatas, sehingga kulkas, dispenser dan rak piring masih seruangan dengan tempat tidur.

Ketiga, ruangan toilet. Toilet terletak di sebelah ruangan tidur, tersedia air bersih yang cukup untuk memenuhi kebutuhan. semua alat yang terdapat diruang mandi selalu terjaga kebersihannya, pencahayaan ruangan toilet cukup baik dengan sirkulasi udara yang baik pula.

\section{SIMPULAN}

Lingkungan psikis di PTKA PIAUD Alauddin cukup baik ditandai dengan pemberian kasih sayang oleh guru ketika anak sedang murung, membangkitkan rasa bosan anak, komunikasi yang baik, memberikan reward, dan lain-lain.

Lingkungan Fisik PTKA PIAUD Alauddin terdiri dari lingkungan indoor dan outdoor. Lingkungan outdoor yang beralaskan lantai tetap aman karena dilapisi dengan karpet puzzle, serta mainan outdoor sebisa mungkin bebas dari bahan berbahaya sebagai salah satu upaya prefentif atau pencegahan agar anak terhindar dari celaka saat beraktifitas di lingkungan outdoor. Namun, karena berada di lingkungan kampus, menyebabkan lingkungan outdoor kadang tidak kondusif karena banyaknya mahasiswa yang lalu lalang. Lingkungan indoor terdiri dari beberapa ruangan yaitu ruangan belajar, ruangan tidur dan toilet. Lingkungan indoor terbilang nyaman karena memiliki pendingin ruangan, bersih dan beralaskan karpet tebal yang kemudian dilapisi kembali dengan karpet puzzle, tata letak fasilitas cukup ideal misalnya rak buku yang mudah dijangkau anak, loker dengan berbagai macam warna, lemari ATK, dan alat mandi dan perlengkapan sholat juga diberi tempat tersendiri. Ruangan tidur dilengkapi speaker dengan music murottal pengantar tidur, kasur yang nyaman dan seprei milik masing-masing anak. Terdapat satu toilet di PTKA PIAUD Alauddin yang letaknya memudahkan guru memantau anak ketika ke toilet. 


\section{DAFTAR PUSTAKA}

Arianto, Miftahcul Rizqi. (2015). Pengaruh Lingkungan Keluarga, Lingkungan Sekolah, dan Motivasi Belajar terhadap Perilaku Belajar Siswa Jurusan Administrasi Perkantoran di SMK Masehi PSAK Ambarawa. Skripsi. https://lib.unnes.ac.id/22214/1/7101411324-s.pdf.

Evertson, Carolyn M. \& Emmer, Edmund T. (2011). Manajemen Kelas untuk Guru Sekolah Dasar. Jakarta: Kencana.

Hidayatulloh, M. Agung. (2014). Lingkungan Menyenangkan dalam Pendidikan Anak Usia Dini: Pemikiran Montessori. Nadwa Jurnal Pendidikan Islam, Vol. 8 Nomor $1 \quad$ April 2014. http://journal.walisongo.ac.id/index.php/Nadwa/article/view/574.

Latif, M., Zubaidah, R., Zukhairina, Afandi, M. (2013). Orientasi Pendidikan Anak Usia Dini Teori dan Aplikasi. Jakarta: Kencana.

Mariyana, R., Nugraha, A., \& Rachmawati, Y. (2010). Pengelolaan Lingkungan Belajar. Jakarta: Kencana.

Mariyana, Rita \& Setiasih, Ocih. (2018). Penataan Lingkungan Belajar Terpadu Untuk Meningkatkan Potensi Kecerdasan Jamak Anak. Pedagogia: Jurnal IImu Pendidikan.

http://ejournal.upi.edu/index.php/pedagogia/article/view/11020.

Mulyasa, H.E. (2012). Manajemen PAUD. Bandung: Remaja Rosdakarya.

Prapsiwi, Dwi. (2012). Pengelolaan Pembelajaran Anak Usia Dini (Studi Kasus di TK Negeri Pembina Boyolali). http://eprints.ums.ac.id/24302/13/02_Artikel_Publikasi.pdf.

Suyadi. (2011). Manajemen PAUD. Yogyakarta: Pustaka Belajar. 